\title{
Metakaolin-based Geopolymers for Removal of Ammonium from Municipal Wastewater
}

\author{
Tatiana Samarina, Esther Takaluoma \\ Kajaani University of Applied Sciences \\ Ketunpolku 1, FI-87101 Kajaani, Finland \\ tatiana.samarina@kamk.fi; esther.takaluoma@kamk.fi
}

\begin{abstract}
A new geopolymer adsorbent based on papermill sludge was prepared in the form of powder and granules and its efficiency for removing ammonium nitrogen from aqueous solution was investigated using batch and column adsorption experiments. The geopolymer was characterized by XRD and XRF. During adsorption tests, an influence of contact time, initial concentration, and adsorbent concentration on ammonium nitrogen removal were studied with powdered form of material. The maximum adsorption capacity of adsorbent towards ammonium nitrogen removed from model solution was found to be $36 \mathrm{mg} / \mathrm{g}$ when the adsorbent dose was $2 \mathrm{~g} / \mathrm{L}$ and $\mathrm{pH} 7.4$, respectively. Synthetic water as well as municipal wastewaters pretreated by flocculation and sedimentation techniques were used in order to prove efficiency of material in a complex matrix. Results obtained indicate that the new geopolymer composition is a promising low-cost material for ammonium nitrogen removal. It has been shown over continuous column experiments that exhausted adsorbent granules could be regenerated with different regeneration agents.
\end{abstract}

Keywords: Adsorption, Geopolymer, Metakaolin, Ammonium Nitrogen, Wastewater treatment, Paper mill sludge, Circular economy, Nutrient removal.

\section{Introduction}

Nitrogen at various species is a common component in fertilizers, and the most widely used form in industry is ammonia. Approximately, $80 \%$ of produced ammonia is converted to solid fertilizers (or applied directly) and the rest $20 \%$ is used in a variety of industrial applications such as in the manufacture of plastics, fibres, explosives or organic nitrogen compounds [1]. Although nitrogen is a renewable resource - atmospheric nitrogen gas from air is used in the Haber-Bosch process - the production of ammonia is high-energy intensive and depends on fossil fuel and gas prices. Roughly, $2 \%$ of the world's total energy is consumed in ammonia production, whereas the process contributes to the world's $\mathrm{CO}_{2}$ emissions substantially [2].

Meanwhile, the EU commission plans to replace $28 \%$ of the use of mineral fertilizers by biomass-based fertilizers by 2025 , reducing the carbon footprint and heavy metal inputs to European soils by $10 \%$. However, sewage sludge is currently excluded from previous estimation due to the problematic nature of using sewage sludge on agriculture land. Today's wastewater treatment methods are not designed to handle harmful substances (heavy metals, medicine traces and contaminants) and produce safe and functioning recycled fertilizers. Moreover, in the EU limits of nutrient discharge become more and more strict (Council Directive 91/676/EEC), which increases the need for additional tertiary or final polishing treatment systems. This creates a need to develop sustainable and commercially viable methods for recovering nutrients from municipal wastewaters.

An aerobic treatment and active sludge process are used at large-scale wastewater treatment plants (WWTP), but temperature limitations, demand of place for aeration basins, and additional sludge formation prevent their use in cold climate conditions. Adsorption technology is suitable for low strength waste streams with a range of pollutant concentrations (1$1000 \mathrm{mg} / \mathrm{L}$ ). Thus, application of adsorbents for nutrient removal from WWTP effluents and artificial lakes is becoming an upcoming technique [3].

Recently, new geopolymer adsorbents based on metakaolin as primary aluminosilicate source was developed and tested [4]. The small-scale piloting test results have shown the ability of the geopolymer adsorbent to remove ammonium from low-laden ammonium streams with simple matrixes as well as with more complex matrixes such as landfill leachate or wastewater streams after primary treatment [5] (the ammonium nitrogen concentration in the streams was 20-50 mg/L). The distinctive features of these sorbents are simple and low-energy synthesis whereas the raw materials (kaolinite clay) are of 
low cost and readily available. The adsorption capacity of those materials toward ammonium is equal or higher than typically used natural zeolites (clinoptilolite, morderite or wollastonite) [4].

The present study is aimed at developing a new formulation of inorganic polymer utilizing low-cost and abundant byproduct material - paper mill sludge contained kaolinite clay - by geopolymerization approach and its application for ammonium nitrogen removal from real matrix. Powdered and granulated forms were evaluated as perspective adsorbent material. The effects of common parameters, such as adsorption time, adsorbent dose, values of initial adsorbate concentration, influence of macrocomponents on adsorption, and composition of adsorbent were also systematically investigated. Possible variants of regeneration were studied in order to reuse exhausted granules after ammonium removal and to estimate possible positive and negative scenarios of their further usability.

\section{Materials and methods}

\subsection{Materials}

Ammonium chloride, sodium hydroxide, sodium silicate were purchased from VWR Chemicals. Sodium silicate ZEOPOL 25 (42-46\%, molar ratio $\mathrm{SiO}_{2}: \mathrm{Na}_{2} \mathrm{O}$ is 2.4-2.6) was purchased from JV Huber. Commercially available metakaolin was obtained from Aquaminerals Finland Oy. Ammonium chloride was dried at $105^{\circ} \mathrm{C}$ for $2 \mathrm{~h}$ prior to use. The paper mill sludge was preliminarily dried at room temperature for several days. The small fibre particles contained in the sludge were ignited, and the remaining kaolinite calcined at $750^{\circ} \mathrm{C}$ for three hours. Sodium chloride, sodium and potassium sulphate used for regeneration were technical grade and used as received (VWR Chemicals).

\subsection{Geopolymer preparation}

Bulk geopolymer was prepared by mixing $50 \mathrm{~g}$ metakaolin recovered from paper mill sludge with alkaline activator in a solid to liquid ratio (S/L) of 1.2. Alkaline activator contained 6-12 M sodium hydroxide and sodium silicate in a weight ratio of 1.2, and obtained geopolymers were named 6MFS, $8 \mathrm{MFS}, 10 \mathrm{MFS}$, and 12MFS, respectively, where the number is indicating the molarity of sodium hydroxide in alkaline activator.

After intense stirring for several minutes, the material was poured into silicon moulds. The mixture was allowed to consolidate at ambient temperature for three days, and the concrete-like monolith crushed with a jaw crasher, sieved, and washed with deionized water until $\mathrm{pH}$ 7.8. A fraction with particle size of $63-125 \mu \mathrm{m}$ was used for batch adsorption experiments.

Granulated geopolymer was formed by mixing calcined metakaolin recovered from paper mill sludge and dosing the alkaline activator $\left(8 \mathrm{M} \mathrm{NaOH}: \mathrm{NaSiO}_{3}=1.2\right)$ until a $\mathrm{S} / \mathrm{L}$ ratio of $3: 1$ was reached. An Eirich laboratory mixer (type EL1) was used for preparing the 8MFS geopolymer in granulated form. After granulation, the granules with particle size 2-4 mm were left to harden for three days. A plastic column (inner height $110 \mathrm{~mm}$, width $37 \mathrm{~mm}$, and volume $120 \mathrm{~mL}$ ) was loaded with granulated geopolymer material and washed with tap water continuously until effluent $\mathrm{pH} 7.8$ before use.

\subsection{Adsorption experiment}

The adsorption experiments were performed using batch equilibration and fixed-bed methods. In the batch method, a desired mass of adsorbent was agitated with $200 \mathrm{ml}$ solution contained nitrogen as ammonium at $30 \mathrm{rpm}$ (overhead shaker) at room temperature for $24 \mathrm{~h}$ to reach equilibrium. The effect of adsorbent dose on ammonium removal was studied by keeping other factors as constant and samples for different dosage were analysed according to EPA Method 350.3 by an ionselective electrode (Orion ThermoFS). Similar experiments were conducted for the study of initial adsorbate concentration, $\mathrm{pH}$ and contact time.

Continuous experiments were performed by pumping samples of synthetic or municipal wastewater at flow rate 0.35 $\mathrm{L} / \mathrm{h}$ through the column filled with $100 \mathrm{~g}$ of geopolymer granules. To obtain a saturated adsorbent prior to regeneration experiments, a solution containing $140 \mathrm{mg} / \mathrm{L}$ of ammonium was pumped through the column using flow rates of $1 \mathrm{~L} / \mathrm{h}$. Both

potassium and sodium salts were used for regeneration experiments with at least five adsorption-desorption cycles. The ammonium concentration in effluents was determined at regular time intervals and the obtained breakthrough curves were used for results interpretation. 


\section{Results and discussion}

\subsection{Characterization of obtained adsorbents}

The elemental composition of samples was measured semiquantitatively with an X-ray fluorescence (XRF) spectrometer (PanAnalytical Minipal 4). The chemical compositions of raw material and prepared adsorbents are listed in Table 1. Aluminium oxide as well as calcium oxide are present in significant quantities, titanium, potassium, and iron oxides are present as impurities. After geopolymerization, the content of $\mathrm{Na}, \mathrm{Si}$ and $\mathrm{Al}$ is increased and loss of ignition (LOI, $950^{\circ} \mathrm{C}$ ) rises from $7.4 \%$ for the calcined metakaolin up to $12.1 \%$ for the geopolymers.

Table 1: Chemical compositions of metakaolin recovered from paper mill sludge and prepared FS geopolymers.

\begin{tabular}{|c|c|c|c|c|c|}
\hline \multirow{2}{*}{ Constituent } & Calcined metakaolin, & \multicolumn{4}{|c|}{ Geopolymer, content (wt. \%) } \\
\cline { 3 - 6 } & content (wt. \%) & 6MFS & 8MFS & 10MFS & 12MFS \\
\hline $\mathrm{Na}_{2} \mathrm{O}$ & - & 6.42 & 6.55 & 7.47 & 8.60 \\
\hline $\mathrm{Al}_{2} \mathrm{O}_{3}$ & 27.7 & 28.5 & 27.3 & 24.6 & 23.9 \\
\hline $\mathrm{SiO}_{2}$ & 32.9 & 39.4 & 40.2 & 32.8 & 30.6 \\
\hline $\mathrm{SO}_{3}$ & 0.17 & 0.04 & 0.05 & 0.05 & 0.07 \\
\hline $\mathrm{K}_{2} \mathrm{O}$ & 0.14 & 0.13 & 0.12 & 0.11 & 0.10 \\
\hline $\mathrm{CaO}$ & 6.39 & 4.35 & 3.75 & 3.99 & 3.77 \\
\hline $\mathrm{Fe}_{2} \mathrm{O}_{3}$ & 0.94 & 0.81 & 0.78 & 0.80 & 0.80 \\
\hline $\mathrm{TiO}_{2}$ & 0.85 & 0.84 & 0.81 & 0.81 & 0.81 \\
\hline
\end{tabular}

Diffractograms of geopolymers were obtained by powder X-ray diffraction method (XRD, a PANnalytical X'Pert PRO MPD diffractometer, Co K $\alpha$ radiations generated at $40 \mathrm{kV}$ and $40 \mathrm{~mA}$, step width of $0.02^{\circ}$, Highscore software 3.0). XRD patterns of the obtained 8MFS geopolymer and geopolymer prepared from commercially available metakaolin (Fig. 1) show the presence of both an amorphous and crystalline structure. The crystalline phase of 8MFS geopolymer is defined by the presence of aluminium and silicon oxide (quartz type), gehlenite is a substantial part of the phase since 8MFS contains up to $3 \%$ of $\mathrm{Ca}$. To compare the structures of $8 \mathrm{MFS}$ and geopolymer made from commercial metakaolin, a reference geopolymer was prepared in accordance with standard procedure [4]. The crystalline phase of latter agrees well with the literature and characteristic peaks of muscovite, quartz, and albite were observed. In a series of 6-12MFS geopolymers, a larger relative yield of amorphous phase were noticed among when the activators with a higher alkali molarity used, while the crystalline phase composition and ratios of minor minerals were generally similar.

\subsection{Influence of initial adsorbate concentration, adsorbent dose, and $\mathrm{pH}$}

Preliminary tests were made to determine the rate in which 6MFS-12MFS adsorbents remove ammonium nitrogen from solutions with 50 and $100 \mathrm{mg} / \mathrm{L}$. The adsorbent 8 MFS showed $12 \pm 2 \%$ better results versus all other formulations and were used in all following experiments.

The effect of initial concentration on ammonium adsorption is measured by varying the concentration of ammonium nitrogen solution from $10 \mathrm{mg} / \mathrm{L}$ to $1000 \mathrm{mg} / \mathrm{L}$ at constant $\mathrm{pH} 7.4$. The experiments were carried out at $22 \pm 5^{\circ} \mathrm{C}$ with an adsorbent dose of $2 \mathrm{~g} / \mathrm{L}$ and contact time of 24 hours. The process of ammonium adsorption was found to extensively increase till $500 \mathrm{mg} / \mathrm{L}$. After the concentration of $500 \mathrm{mg} / \mathrm{L}$, the ammonium adsorption continues in slower rate (Fig. 2). The removal rate at $50 \mathrm{mg} / \mathrm{L}$ (level of ammonium concentration in WWTP water) was $32 \pm 5 \%(n=3, P=0.95)$. 

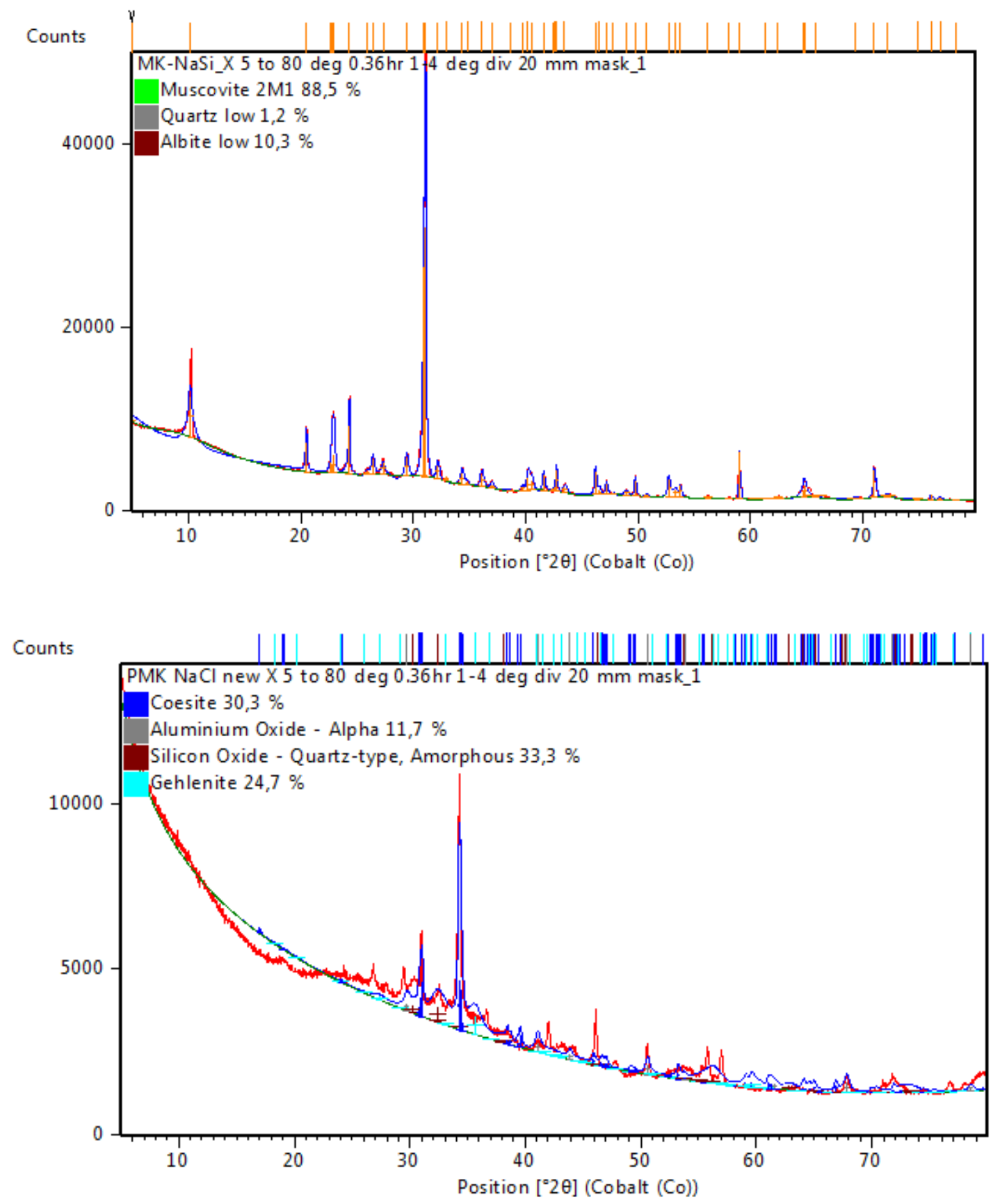

Fig. 1: XRD patterns of reference MK geopolymer (upper) and 8MFS geopolymer (bottom).

Raising the initial ammonium concentration to $500 \mathrm{mg} / \mathrm{L}$ allows the geopolymer to reach adsorption capacity up to $25 \mathrm{mg} / \mathrm{g}$. Compared to other adsorbents, such as mineral and organic materials, this adsorption capacity is relatively high and ammonium could be more efficiently removed from aqueous solutions. The Freundlich isotherm was found to fit the best and the maximal capacity calculated with it was $36 \mathrm{mg} / \mathrm{g}$. 

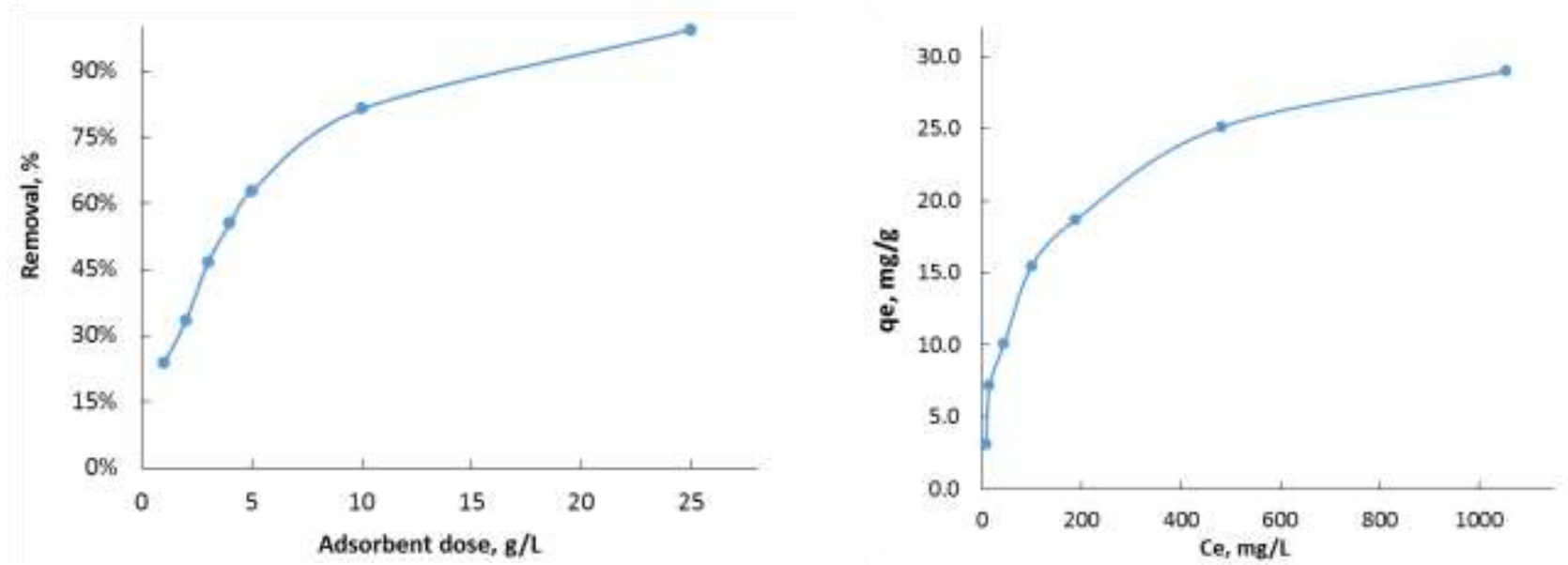

Fig. 2: Effect of geopolymer dose on ammonium removal (left) and removal capacity dependence on equilibrium ammonium concentration (right).

The effect of adsorbent dosage. The effects of varying the geopolymer dose on the ammonium removal efficiency were studied at $24 \mathrm{~h}$ contact time and $50 \mathrm{mg} / \mathrm{L}$ of ammonium ion solutions. The adsorbent dose was varied from 1 to $25 \mathrm{~g} / \mathrm{L}$. As seen from Fig. 2, when the geopolymer dose increased from 1 to $10.0 \mathrm{~g} / \mathrm{L}$, the ammonium removal efficiency increased from 24 to $84 \%$, and the complete removal of ammonium ions from solution were reached at adsorbent dose of $25 \mathrm{~g} / \mathrm{l}$. The increase in ammonium removal efficiency with the increase of the adsorbent amount might be explained by the increase in surface area and available exchange sites. It worth mentioning that at concentration of $50 \mathrm{mg} / \mathrm{L}$ as ammonium nitrogen, which is typical for WWTP secondary effluent, the capacity was $3.5 \mathrm{mg} / \mathrm{g}$ for adsorbent dose of $10 \mathrm{~g} / \mathrm{L}$ allowing to remove $84 \%$ of ammonium and reach required level of purification according to most environmental permits.

Contact time and $\mathbf{p H}$. The maximum removal efficiency of $32 \%$ with adsorbent dose $2 \mathrm{~g} / \mathrm{L}$ could be achieved after $24 \mathrm{~h}$, though approximately $20 \%$ of ammonium were removed already within the first hour (Fig. 3). It is important to highlight that removal rate up to $31 \%$ was approached at concentration of $100 \mathrm{mg} / \mathrm{L}$ ammonium after 3 hour of contact time.

The effect of $\mathbf{p H}$ on removal ammonium was studied in acetate or borate buffer solutions. The removal of ammonium by 8 MFS geopolymer remained at maximum rate in a narrow range. This might be attributed to the fact that maximal positive charge of the metakaolin adsorbent surface is most likely to be at $\mathrm{pH} 7.1$ [4]. Steady increase in the removal rate after $\mathrm{pH}$ 8.7 presumably related with loss of ammonium as ammonia.
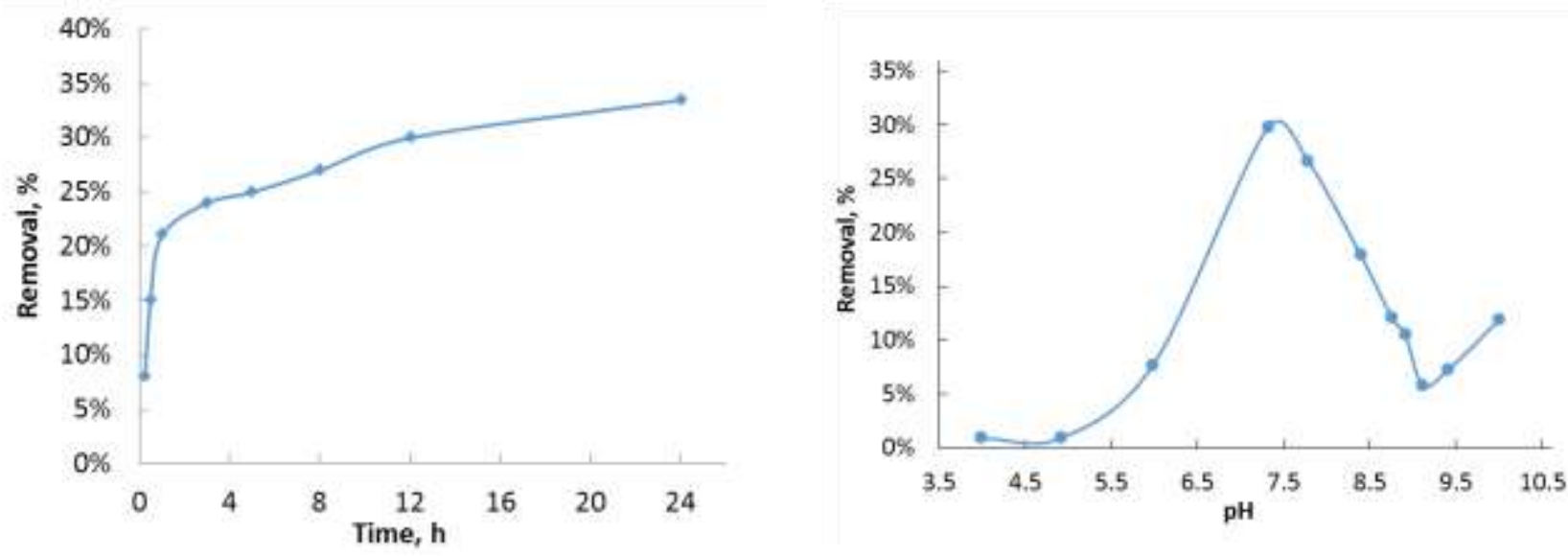

Fig. 3: Effects of contact time (left) and $\mathrm{pH}$ (right) on ammonium nitrogen removal (concentration $8 \mathrm{MFS} 2 \mathrm{~g} / \mathrm{L}$, initial ammonium concentration $50 \mathrm{mg} / \mathrm{L})$.

Competitive cations. To explore the selectivity of geopolymers in the presence of other alkali- and alkali-earth metal cations, the batch adsorption experiment with different ratios of metal to ammonium were carried out. Despite the existence 
of sodium in the solution up to level $400 \mathrm{mg} / \mathrm{L}$ both reference MK and FS geopolymers remained the ability to remove ammonium at the high levels. Alkali-earth metals had a strong impact on removal efficiency of ammonium already at concentrations of $25 \mathrm{mg} / \mathrm{L}$ of calcium and $50 \mathrm{mg} / \mathrm{L}$ of magnesium. However, 8MFS adsorbent had lower selectivity in comparison with reference MK geopolymer.

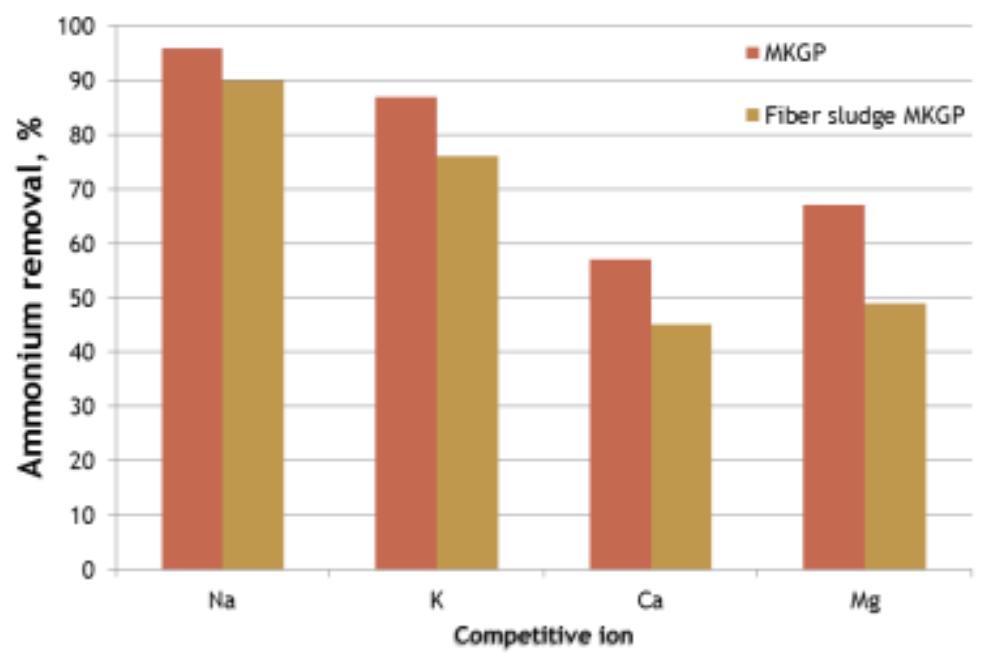

Fig. 4: The removal efficiency of ammonium on reference and 8MFS geopolymers in the presence of competitive ions.

Synthetic water and real samples. To evaluate synergetic impact of foreign ions, which could co-exist in treated solutions, adsorption experiments with synthetic and secondary effluent WWTP water were conducted. The composition of tested waters is presented in Table 2 . For adsorbent dose $10 \mathrm{~g} / \mathrm{L}$, the removal for synthetic water was $48 \%$ with $\mathrm{MK}$ geopolymer and 58\% for 8MFS geopolymer. For secondary effluent, the removal for the same adsorbent dose was $77 \%$ and $84 \%$ with MK and 8 MFS geopolymers, respectively.

Table 2: Content of major elements and competitive ions.

\begin{tabular}{|l|c|c|}
\hline Element & Synthetic water, mg/L & Secondary effluent, mg/L \\
\hline $\mathrm{Na}$ & 300 & $\mathrm{n} / \mathrm{d}$ \\
\hline $\mathrm{Ca}$ & 100 & 27 \\
\hline $\mathrm{Mg}$ & 100 & 4.4 \\
\hline $\mathrm{K}$ & 15 & 0.2 \\
\hline $\mathrm{NH}_{4}-\mathrm{N}^{*}$ & 44 & 31 \\
\hline
\end{tabular}

*target contaminant, as $\mathrm{N} \mathrm{mg/L;} \mathrm{not} \mathrm{determined.}$

\subsection{Regeneration column experiment}

The granulated form of adsorbent was used to consider of adsorbent regeneration. Sodium chloride and sulfate, and potassium sulfate and phosphate were studied as potential regeneration solutions (with sodium/potassium concentration $1 \mathrm{M}, \mathrm{pH}$ 12). Each of the regeneration solutions was pumped at a flow rate of $0.35 \mathrm{~L} / \mathrm{h}$ and the residence time was 5.5 min. For treated solutions contained only ammonium, regeneration with sodium chloride and sulphate gave $0.61 \mathrm{~g}$ ammonium recovered, potassium sulphate gave $0.83 \mathrm{~g}$ ammonium regenerated, and potassium phosphate was least effective (only $0.29 \mathrm{~g}$ ). However, it was found that after regenerating 8MFS with potassium salts, the removal efficiently 
towards ammonium was reduce substantially, up to $55 \%$. The removal capability could be returned, though, after $24 \mathrm{~h}$ contact time with $5 \mathrm{M}$ sodium chloride.

For further experiments with synthetic water sodium salts were selected. Sodium sulfate showed better results during five cycles of continuous sorption-desorption experiment, only $34 \%$ of an initial overall capacity were lost. Sodium chloride regenerant was also efficient, but only $55 \%$ of ammonium could be removed after $5^{\text {th }}$ cycle.

\section{Conclusion}

A new geopolymer adsorbent composition was proposed with the aim of recovering ammonium from low-laden streams and improving the negative impact of nitrogen pollution. The morphological analysis was done with XRD and XRF. The maximum adsorption capacity of metakaolin-based geopolymer to take up ammonium nitrogen from aqueous solution has been determined and was $36 \mathrm{mg} / \mathrm{g}$. The results show that removal of ammonium nitrogen varies with changes in initial concentration, adsorbent dose and contact time, however the process is tolerant to temperature. The removal rate of ammonium nitrogen for a solution of concentration $50 \mathrm{mg} / \mathrm{L}$ with $10 \mathrm{~g} / \mathrm{L}$ of geopolymer for synthetic and municipal wastewater is reported as $58 \%$ and $84 \%$. Ammonium removal using this type of adsorbent can be a basis for designing of various commercial purification applications.

\section{Acknowledgements}

This study was conducted as part of the WaterPro project (project number A74635), funded mainly by the European Regional Development Fund (EAKR, Keski-Pohjanmaan Liitto/Kainuun Liitto). The authors wish to thank Mrs. Eeva Seppänen and Mrs. Marjukka Hyyryläinen for assisting with the laboratory work and analyses.

\section{References}

[1] I. Dincer, Y. Bicer, "Ammonia," in Comprehensive Energy Systems, I. Dincer, Ed. Amsterdam: Elsevier Inc., vol. 2, pp. 1-39. 2018.

[2] Report of International Energy Agency IEA. (2007, June). Tracking Industrial Energy Efficiency and CO2 Emissions [Online]. Available: https://www.iea.org/publications/freepublications/publication/tracking_emissions.pdf.

[3] J. Huang, N. R. Kankanamge, C. Chow, D. T. Welsh, T. Li, and P. R. Teasdale, "Removing ammonium from water and wastewater using cost-effective adsorbents: A review," J. Environ. Sci., vol. 63, pp. 174-197, 2018.

[4] T. Luukkonen et al., "Optimization of the metakaolin geopolymer preparation for maximized ammonium adsorption capacity," J. Mater. Sci., vol. 52, no. 16, pp. 9363-9376, 2017.

[5] T. Luukkonen et al., "Removal of ammonium from municipal wastewater with powdered and granulated metakaolin geopolymer," Environ. Technol., vol. 39, no. 4, pp. 414-423, 2018. 